\title{
An atypical corallum morphology in a species of Pocillopora
}
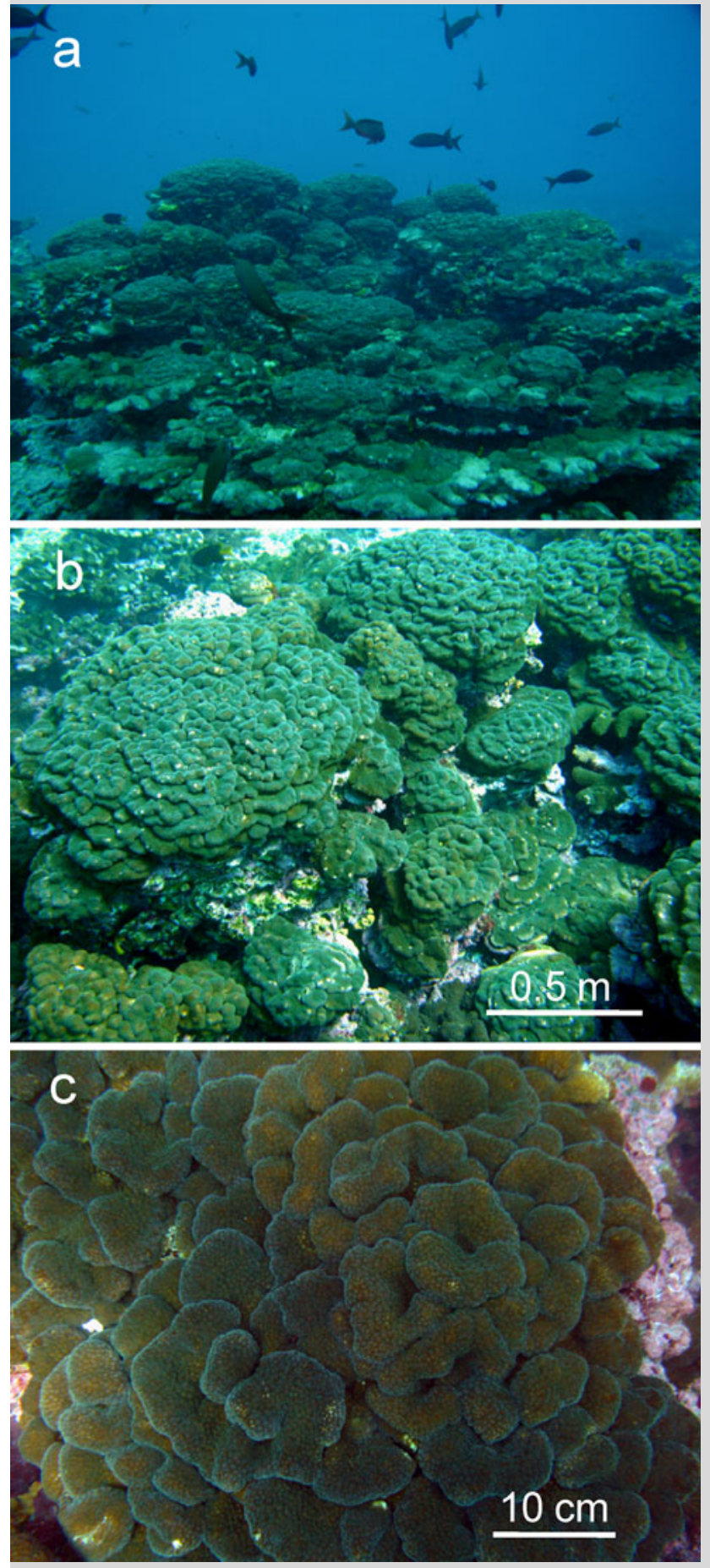

Fig. 1 a General view of Pocillopora sp. aggregation at El Arrecife, Malpelo's main coral formation. b Submassive corallum morphology. c Surface detail
Species of the genus Pocillopora are renowned for their remarkable morphological variability and phenotypic plasticity, which hamper progress in resolving their taxonomy and systematics. Some species exhibit a wide range of branch thickness in response to environmental gradients (Veron 2000). While the degree of compactness may increase with water energy in P. damicornis (Todd 2008), neither laboratory experiments nor field observations have revealed transitions from branching to massive growth patterns. Here, we report a previously unknown corallum morphology in a species of Pocillopora.

A conspicuous aggregation of large colonies $(0.5-1 \mathrm{~m}$ in diameter) of Pocillopora sp. covering an area of $\sim 50 \mathrm{~m}^{2}$ was observed at $11 \mathrm{~m}$ depth at Malpelo Island $\left(4^{\circ} 00^{\prime} 08^{\prime \prime} \mathrm{N}-81^{\circ} 36^{\prime} 31^{\prime \prime} \mathrm{W}\right)$, Eastern Tropical Pacific (ETP). The colonies exhibited a very unusual growth form with a tightly submassive, hemispherical corallum (Fig. 1a), composed of thick, short, and flattened branches growing horizontally in an imbricate pattern, forming a flower-like structure (Fig. 1b, c). Verrucae were short and uniformly distributed on branch surfaces (Fig. 1c). These colonies did not resemble any Pocillopora species described so far (Veron 2000). Additionally, there was no consensus among experts consulted regarding the taxonomic status of these colonies; most had never seen this morphology anywhere else in the ETP or the Indo-Pacific. Only a single similar colony was observed in Panama (A. Baker, personal communication). Thus, the morphological evidence suggests a new species.

Alternatively, this unusual corallum form may represent an extreme case of intraspecific morphological variability or phenotypic plasticity. Strong waves and currents are major factors affecting coral communities at Malpelo (Zapata and Vargas-Ángel 2003) and could promote or mediate morphological variation within morphospecies. For the majority of corals, however, the role of the environment on morphological variation is poorly understood (Todd 2008). Resolving this issue will require detailed work involving controlled transplant experiments and molecular genetic analyses.

Acknowledgments We thank A. Baker, C. Birkeland, J. Cortés, C. Jiménez, P. Glynn, H. Guzmán, H. Reyes-Bonilla, and J. E. N. Veron for examining photographs and their valuable comments. Research at Malpelo was supported by Fundación Malpelo, UAESPNN, DIMAR, and INVEMAR.

\section{References}

Todd PA (2008) Morphological plasticity in scleractinian corals. Biol Rev 83:315-337

Veron JEN (2000) Corals of the world, vol 2. Australian Institute of Marine Science, Townsville

Zapata FA, Vargas-Ángel B (2003) Corals and coral reefs of the Pacific coast of Colombia. In: Cortés J (ed) Latin American coral reefs. Elsevier, Amsterdam, pp 419-447

A. Rodriguez-Ramirez ( $\square)$

The University of Queensland, St. Lucia, Brisbane, QLD 4072,

Australia

e-mail: alberto.rodriguez@uq.edu.au

F. A. Zapata

Departamento de Biología, Universidad del Valle, Apartado Aéreo, 25360 Cali, Colombia 